\title{
Reconstructive surgical management of cryptomenorrhoea because of complete vaginal agenesis
}

\author{
Krishna Dahiya, Ranjita Bains
}

Department of Obstetrics and Gynecology, Pt. B. D. Sharma PGIMS, Rohtak, India.

Email: krishnadahiya@rediffmail.com; drkrishnadahiya@gmail.com

Received 10 October 2011; revised 23 November 2011; accepted 7 December 2011.

\begin{abstract}
Background: The Vagina is a composite structure formed partly from the mullerian duct and partly from urogential sinus. Most of the patients with mullerian agenesis have small rudimentary uterus without any endometrial cavity, $7 \%-8 \%$ may have functioning uterus. Case: A 15 years old girl admitted with primary amenorrhea, cyclical abdominal pain, hematometra and complete vaginal agenesis. Surgical correction is the mainstay of treatment in patients with functioning uterus and absent vagina. Vaginoplasty was done to reconstruct a neovagina using amnion graft and establish uterovaginal continuity. In this case we have used only perineal approach to dissect the neovagina and identify the cervix with formation of a patent drainage tract and adequate vaginal length of $9 \mathrm{~cm}$. Conclusion: In rare cases of obstructed functioning uterus by complete vaginal agenesis, vaginoplasty effectively restores anatomy and function by an overall minimal operative morbidity. Human amnion provides excellent results in neovaginal reconstruction.
\end{abstract}

Keywords: Vaginal Agenesis; Hematometra

\section{INTRODUCTION}

Vaginal agenesis is a congenital anomaly of the female genital tract and may occur as isolated developmental defect or as part of a complex of anomalies. Vaginal agenesis is estimated to occur in 1 in 4000 - 5000 live female births [1]. It is most commonly associated with MayorRokitansky-Kuster-Hauser (MRKH) syndro-me and androgen insensitivity syndrome [2,3]. Isolated defects in the development of vagina though very rare but have been reported in literature [4]. We here report a similar case of hematometra with complete vaginal agenesis.

\section{CASE REPORT}

A 15 year old girl who had normal female genotype and normal secondary sexual characteristics presented with primary amenorrhea and cyclic pelvic pain for six months on examination her vitals were stable with pulse 84 per minute and BP 120/84 mm of Hg. Skeletal, Cardiovascular and respiratory system examination were normal. Otological anomalies were ruled out. On per abdomen examination uterus was enlarged to 14 week size slightly deviated to right side. Pelvic examination revealed vaginal dimple without a normal vaginal orifice (Figure 1). Same enlarged uterus was palpated on per rectal examination. USG showed uterus $14 \mathrm{~cm} \times 12 \mathrm{~cm} \times 9 \mathrm{~cm}$ with collection in endometrial cavity with internal echoes suggestive of hematometra. MRI revealed dextro-rotated uterus with uterus and cervix distended with a collection, hyperintense in T1W and hypointense in T2W (Figure 2). Bilateral ovaries were normal. IVP showed no urological abnormality.

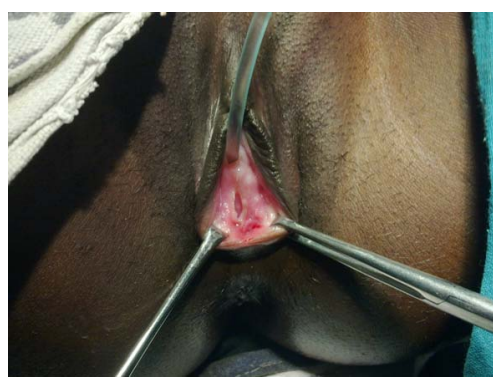

Figure 1. preoperative photograph.

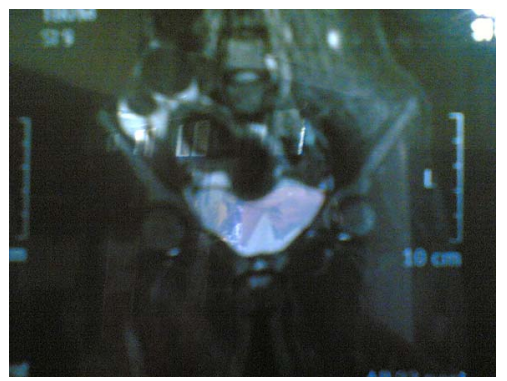

Figure 2. MRI photograph showing uterus with cervix. 
Surgical treatment with a preoperative diagnosis of vaginal agenesis with hematometra was scheduled after a detailed counseling regarding the surgical method and its possible complications. The operation began with a transverse incision at the site of vaginal dimple. A potential space was created between the bladder and urethra in front and rectum behind by blunt dissection. The catheter was palpated in bladder and assistant's finger in rectum to avoid vesical or rectal injury during the dissection. The dissection continued until a neovagina was obtained with a length of $9 \mathrm{~cm}-10 \mathrm{~cm}$ and a diameter of $3 \mathrm{~cm}$. On per vaginum examination a well developed cervix was felt and a single uterus enlarged to fourteen week size. An incision was given and a uterine sound was introduced. Cervix dilated with dilators and hematometra drained. A vaginal mould covered with amnion graft was inserted into the neovagina with a Foley's catheter placed in the cervix; its balloon was insufflated with $10 \mathrm{~mL}$ saline. The bladder catheter and the mould were maintained for 7 days postoperatively. After removing the mould, the patient was advised to use the mould constantly for 2 months postoperatively. The mould had to be cleaned on a daily basis, and the patient was explained the method of cleaning and inserting the mould on her own. For lubrication and to support an enhanced epithelization, the mould was covered with $0.1 \%$ estriol cream just before the insertion. The patient was discharged from hospital on fourteenth postoperative day with an uneventful postoperative course. On follow up visit her neovagina was patent on examination with normal cervix and uterus (Figure 3).

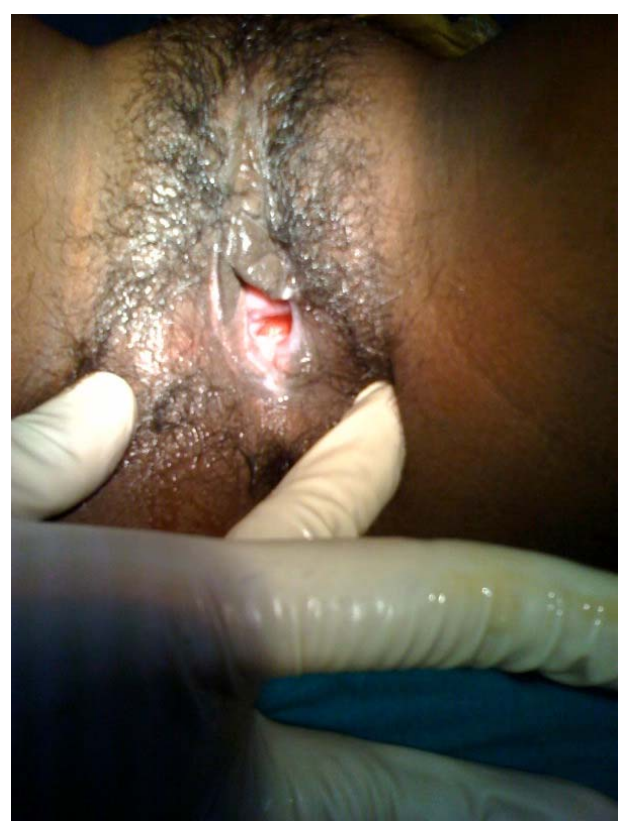

Figure 3. Postoperative follow up after 6 weeks showing patent neovagina.

\section{DISCUSSION}

Normal vagina develops from the fusion of mesodermal müllerian ducts and the endodermal urogenital sinus. The caudal ends of the mullerian ducts form the mullerian tubercle at the dorsal wall of the urogenital sinus at 9 weeks. Mullarian tubercle is obliterated to form the vaginal plate. At $16 \mathrm{wk}-18 \mathrm{wk}$ the central core breaks down to form the vaginal lumen (20 weeks). The upper $2 / 3$ of the vagina is formed by mullerian tubercle and lower one third by urogenital sinus. Developmental failure of the sinovaginal bulbs can lead to vaginal agenesis. Müllerian agenesis can be partial or complete. Partial müllerian agenesis is more rarely encountered and is characterized by a normal uterus and small vaginal pouch distal to the cervix [5,6] Complete müllerian agenesis (MRKH syndrome) is the most common variant encountered and it is characterized by congenital absence of the vagina and the uterus in $90 \%$ - 95\% of cases. Two types of this syndrome are described.

Type-I MRKH syndrome is characterized by an isolated absence of the proximal two thirds of the vagina, whereas type II is marked by other malformations; these include vertebral, cardiac, urologic (upper tract), and otologic anomalies. Young patients present with amenorrhea with or without cyclical pelvic pain in MRKH-1 syndrome. Surgical correction is the mainstay of treatment in patients with functioning uterus and absent vagina. Non-surgical creation of vagina by progressive dilatation of the pseudohymen membrane (Frank technique) is the appropriate first-line approach in the majority of patients. In the literature, although more than 10 surgical procedures for neovaginal reconstruction have been described so far, an ideal approach has not yet been identified:[7]. Several investigators have described modifications of the Abbe McIndoe procedure, including methods that use amnion, peritoneum, intercede, artificial dermis and recombinant basic fibroblast growth factor, autologous buccal mucosa and rotational flap procedures using the pudendal, thigh, gracilis myocutaneous, labia minora and other fasciocutaneous flaps [8-11]. In addition bowel vaginoplasty using segment of sigmoid colon or ileum is also used and some centres are now using laparoscopic approach for it. Latest techniques include robotic sigmoid vaginoplasty and laparoscopic formation of neovagina followed by extraperitoneal traction on Foley's catheter [12,13]. Many authors have used amnion as graft in vaginoplasty and reported excellent results $[11,12]$. We have chosen amnion as graft because it is readily available, cheap, no problem of painful donor site, provide a protective cover over wound because of production of bactericidal enzymes, no problem of immune rejection since amnion does not express histocompatability antigen. 
In such patients the commonly used technique combining McIndoe Vaginoplasty along with an abdominal approach to drain the hematometra has been reported with good results. In this case we have used only perineal approach to dissect a neovagina and identify the cervix with formation of a patent drainage tract and a total vaginal length of $9 \mathrm{~cm}$. The morbidity of the patient was decreased with relief of symptoms, formation of a functional vagina and absence of an abdominal scar with no breach in the integrity of uterus. Using an appropriate vaginal mould is one of the keys to achieving a successful result in neovaginal reconstruction. Vaginal moulds which are used to prevent re-stenosis of created neovagina may be associated with a lot of problems. Poor drainage, graft maceration, sloughing, and graft detachment may be caused by non ideal vaginal moulds and lead to an unsatisfactory reconstruction $[8,9]$.

Here we use a vaginal mould made of dental material hollow from inside. An intrauterine placement of Foley's catheter allows continuous drainage and maintains a patent tract in early post-operative period. On follow up visits the patient was seen to have a total vaginal length of $9 \mathrm{~cm}$ with epithelised patent vagina. She was advised to use the mould coated with estradiol cream continuously for 2 months with use of a disinfectant for cleaning. Mould was to be removed only while urinating or defecating. Later she was told to use it for another 3 months at night.

Preservation of the uterus should always be attempted in patients with in patients of vaginal agenesis with hematometra. Thus reproductive capacity is preserved, although the patients should be aware of the fact that although the possibility of spontaneous pregnancy exists, assisted reproduction techniques may eventually be necessary. Repeated episodes of hematometra, endometriosis have been reported in conservative management of such cases. In some cases, however due to the recurrent obstruction, radical treatment by hysterectomy has been reported as a last option [13-15].

\section{REFERENCES}

[1] Saxena, A.K. and Herman, M.I. (2009) Vaginal Atresia. Webpage. Cited June 02, 2009.

http://emedicine.medscape.com/article/954110-print

[2] Saraf, S. and Saraf, P. (2007) McIndoe vaginoplasty: Revisited. International Journal of Gynecology and Obstetrics, 6, Online Journal.
[3] Gupta, N.P. and Ansari, M.S. (2002) Mayer-RokitanskyKuster-Hauser (MRKH) syndrome-A review. Indian Journal of Urology, 18, 111-116.

[4] ACOG Committee Opinion (2002) Nonsurgical diagnosis and management of vaginal agenesis. International Journal of Gynecology and Obstetrics, 79, 167-170. doi:10.1016/S0020-7292(02)00326-0

[5] Jones, H.W. JR. and Scott, W.M. (1958) Hermaphroditism, genital anomalies, and related endocrine disorders. 2nd Edition, Williams \& Wilkins Co., Baltimore, 327.

[6] Jones, H.W. Jr. and Wheeless, C.R. (1969) Salvage of the reproductive potential of women with anomalous development of the muellerian ducts. American Journal of $\mathrm{Ob}$ stetrics and Gynecology, 104, 348-352.

[7] Seccia, A., Salgarello, M., Sturla, M., Loreti, A., Latorre, S. and Farallo, E. (2002) Neovaginal reconstruction with the modified mcIndoe technique: A review of 32 cases. Annals of Plastic Surgery, 49, 379-384. doi:10.1097/00000637-200210000-00008

[8] McIndoe, A. (1950) The treatment of congenital absence and obliterative conditions of the vagina. British Journal of Plastic Surgery, 2, 254-267.

[9] Yu, K.J., Lin, Y.S., Chao, K.C., Chang, S.P., Lin, L.Y. and Bell, W. (2004) A detachable porous vaginal mould facilitates reconstruction of a modified mcIndoe neovagina. Fertility and Sterility, 81, 435-439. doi:10.1016/j.fertnstert.2003.06.032

[10] Chohan, A., Burr, F., Mansoor, H. and Falak, T. (2006) Amnion graft in vaginoplasty-An experience at 3 teaching hospitals of Lahore. Biomedica, 22, 21-24.

[11] Fotopoulou, C., Sehouli, J., Gehrmann, N., Schoenborn, I. and Lichtenegger, W. (2009) Functional and anatomical results of amnion vaginoplasty in young women with Mayer-Rokitansky-Kuster-Hauser syndrome. Fertility and Sterility, (Epub ahead of print).

[12] Fedele, L., Bianchi, S., Zanconato, G. and Raffaelli, R. (2000) Laparoscopic creation of neovagina in patients with rokitansky syndrome: Analysis of 52 cases. Fertility and Sterility, 74, 384-389. doi:10.1016/S0015-0282(00)00620-8

[13] Cai, B., Zhang, J.R., Xi, X.W., Yan, Q. and Wan, X.P. (2007) Laparoscopically assisted sigmoid colon vaginoplasty in women with Mayor-Rokitansky-Kuster-Hauser syndrome: Feasibility and shortterm results. British Journal of Obstetrics and Gynaecology, 114, 1486-1492. doi:10.1111/j.1471-0528.2007.01514.X

[14] Rana, A., Gurung, G., Begum, S.H., Adhikari, S. and Neupane, B.B. (2007) Hysterectomy for hematometra in a 15-year-old mentally handicapped girl with congenital cervicovaginal agenesis and concomitant ovarian adenoma. Journal of Obstetrics and Gynecology, 34, 105-107. doi:10.1111/j.1447-0756.2007.00726.x

[15] Roszaman, R. and Ghazali, I. (2006) Vaginal and cervical agenesis-Hysterectomy in a young girl. Internal Medicine Journal, 5. 